\title{
Electrophysiological Effects of Carvedilol on Rabbit Heart Pacemaker Cells
}

\author{
Ayumi YokoYama, ${ }^{1} \mathrm{MD}$, Nobuyuki SATO,${ }^{1} \mathrm{MD}$, Yuichiro KawAmura, ${ }^{1} \mathrm{MD}$, \\ Naoyuki HASEBE, ${ }^{1} \mathrm{MD}$, and Kenjiro KIKUCHI, ${ }^{1} \mathrm{MD}$
}

\begin{abstract}
SUMMARY
The electrophysiological effects of carvedilol, a $\beta$-blocking agent with vasodilating actions, have been studied on rabbit pacemaker cells using the whole-cell patch clamp technique. Nystatin-perforated patch recordings from the sinoatrial (SA) and atrioventricular (AV) nodes demonstrated that $1-3 \mu \mathrm{M}$ of carvedilol caused a decrease in the spontaneous firing frequency, depolarization of the maximal diastolic potential, and prolongation of the action potential duration in both species. Voltage clamp experiments were performed using SA and AV node myocytes to identify and define the carvedilolinduced changes in the $\mathrm{Ca}^{2+}$ current, $\mathrm{I}_{\mathrm{Ca}}$, delayed rectifier $\mathrm{K}^{+}$current, $\mathrm{I}_{\mathrm{K}}$, and hyperpolarization-activated inward current, $\mathrm{I}_{\mathrm{f}}$. In the SA node cells, $1 \mu \mathrm{M}$ of carvedilol blocked $\mathrm{I}_{\mathrm{K}}$, $\mathrm{I}_{\mathrm{Ca}}$, and $\mathrm{I}_{\mathrm{f}}$ by $72 \%, 47 \%$, and $22 \%$, respectively. In the AV node cells, the corresponding reductions were $64 \%\left(\mathrm{I}_{\mathrm{K}}\right)$ and $46 \%\left(\mathrm{I}_{\mathrm{Ca}}\right)$, respectively. In both the SA and AV nodes the decrease in $I_{K}$ appeared to be mainly due to the rapidly activating component of the delayed rectifier, $\mathrm{I}_{\mathrm{Kr}}$, since the high dose of carvedilol blocked $\mathrm{I}_{\mathrm{K}}$ in the SA and AV nodes to a submaximal degree. In conclusion, effective doses of carvedilol have classical class III antiarrhythmic actions and a negative chronotropic effect resulting from the inhibition of $\mathrm{I}_{\mathrm{K}}$ and $\mathrm{I}_{\mathrm{Ca}}$. Both actions may be efficacious for treating supraventricular tachyarrhythmias. (Int Heart J 2007; 48: 347-358)
\end{abstract}

Key words: Sinoatrial (SA) node, Atrioventricular (AV) node, Whole-cell patch clamp, $\mathrm{Ca}^{2+}$ current $\left(\mathrm{I}_{\mathrm{Ca}}\right)$, Delayed rectifier $\mathrm{K}^{+} \operatorname{current}\left(\mathrm{I}_{\mathrm{K}}\right)$, Hyperpolarization-activated inward cur$\operatorname{rent}\left(\mathrm{I}_{\mathrm{f}}\right), \beta$-blocking agent

CARVEDILOL is a new type of $\beta$-adrenoreceptor blocking agent with multiple potencies. In addition to its nonselective $\beta$-adrenergic blocking effect, it also has $\alpha_{1}$ adrenergic blocking actions, ${ }^{1)}$ antioxidant properties, ${ }^{2,3)} \mathrm{Ca}^{2+}$ blocking effects, ${ }^{4)}$ and inhibitory effects on cardiac remodeling and myocyte apoptosis. ${ }^{5-7)}$ Recently, this agent has attracted increasing attention among cardiologists following positive outcomes in various clinical trials. For example, it has been shown that carvedilol produces dose-related improvements in left ventricular function and a

From the ${ }^{1}$ First Department of Internal Medicine, Asahikawa Medical College, Hokkaido, Japan.

Address for correspondence: Nobuyuki Sato, MD, First Department of Internal Medicine, Asahikawa Medical College, Midorigaoka Higashi 2-1-1, Asahikawa, Hokkaido 078-8510, Japan.

Received for publication August 14, 2006.

Revised and accepted March 2, 2007. 
reduction in mortality in patients with chronic heart failure, ${ }^{8-12)}$ and decreases secondary cardiac events after myocardial infarction. ${ }^{13)}$ Furthermore, it has also been suggested that this agent might have antiarrhythmic properties since it was reported to reduce the occurrence of sudden cardiac death in some clinical studies. ${ }^{8,10-12)}$ Indeed, it has been demonstrated that carvedilol suppresses ventricular arrhythmias in patients with hypertension, angina pectoris, and congestive heart failure, and reduces the frequency of lethal ventricular arrhythmias in severe heart failure. ${ }^{12,14)}$ However, it is not clear whether the reduction in these arrhythmic events is due to a direct action of the drug or secondary effects caused by improved cardiac function.

In animal experimental models, carvedilol has been shown to reduce reperfusion arrhythmias and digitalis-induced ventricular arrhythmias. ${ }^{15-17)}$ Recently, it has been reported that carvedilol can inhibit the rapidly activating component of the delayed rectifier $\mathrm{K}^{+}$current $\left(\mathrm{I}_{\mathrm{Kr}}\right)$ and L-type $\mathrm{Ca}^{2+}$ current $\left(\mathrm{I}_{\mathrm{Ca}}\right)$ in rabbit ventricular myocytes. ${ }^{4)}$ Furthermore, it has recently been shown that carvedilol inhibits human ether-a-go-go related gene (HERG) potassium channels. ${ }^{18)}$ Thus, carvedilol has been recognized to have the ability to slow cardiac repolarization and produce a negative chronotropic effect. Consistent with this, a significant reduction in sinus node beating was observed in patients with acute myocardial infarction. ${ }^{13)}$ However, the ionic mechanisms underlying the carvedilol-induced action potential prolongation and negative chronotropic actions have not yet been fully elucidated. Since the pacemaker tissue of the sinoatrial (SA) and atrioventricular (AV) nodes is responsible for the pacemaking activity of the heart and is related to some types of arrhythmias such as sinoatrial nodal reentrant tachycardia, AV nodal reentrant tachycardia, and AV reentrant tachycardia using an accessory pathway, it is important to ascertain the effects of carvedilol on the automaticity of the nodal cells. Hence, we investigated the ionic mechanisms underlying the carvedilol-induced action potential prolongation and negative chronotropic actions using rabbit SA and AV node cells.

\section{METHODS}

This investigation conformed to the Guidelines for the Care and Use of Laboratory Animals of Asahikawa Medical College.

Isolation of nodal cells: Rabbits weighing $1.5-2.0 \mathrm{~kg}$ were anesthetized with sodium pentobarbital $(50 \mathrm{mg} / \mathrm{kg})$. The heart was quickly removed and then perfused retrogradely for 5 minutes on a Langendorff apparatus $\left(37^{\circ} \mathrm{C}, 80 \mathrm{~cm} \mathrm{H}_{2} \mathrm{O}\right)$ with a Tyrode's solution containing $1.8 \mathrm{mM} \mathrm{CaCl}_{2}$ to remove the blood, $\mathrm{Ca}^{2+}$-free Tyrode for 10 minutes, and then $\mathrm{Ca}^{2+}$-free Tyrode containing $0.04 \mathrm{mg} / \mathrm{mL}$ of collagenase (Yakult Co. Ltd., Tokyo). After 8 minutes of enzyme treatment, the ana- 
tomical SA and AV nodal regions were removed, and the surrounding tissues were dissected away. The final preparations were cut into small pieces and stirred in $\mathrm{Ca}^{2+}$-free HEPES-buffered Tyrode solution containing $1.0 \mathrm{mg} / \mathrm{mL}$ of collagenase (Sigma type 1), $0.3 \mathrm{mg} / \mathrm{mL}$ of elastase (Boehringer Mannheim, Germany), and $1 \%$ bovine serum albumin (BSA, Sigma Co. Ltd. Fraction V) for the SA nodal cells, and $1.0 \mathrm{mg} / \mathrm{mL}$ of collagenase and $1 \%$ BSA for the AV nodal cells. Every 3 minutes, aliquots of these solutions were aspirated and placed in KB solution. The isolated cells were collected by centrifugation for 5 minutes, and stored in $\mathrm{KB}$ solution with $1 \% \mathrm{BSA}$ at $4^{\circ} \mathrm{C}$.

Solutions and drugs: The HEPES-buffered Tyrode solution contained (in $\mathrm{mM}$ ): $\mathrm{NaCl} 143, \mathrm{KCl} 5.4, \mathrm{MgCl}_{2}$ 0.5, $\mathrm{CaCl}_{2}$ 1.8, HEPES 5.0, and glucose $5.5(\mathrm{pH}=7.4$ adjusted with $\mathrm{NaOH}$ ). The $\mathrm{KB}$ solution contained (in $\mathrm{mM}$ ): $\mathrm{KOH} 70$, L-glutamic acid 50, $\mathrm{KCl} 40, \mathrm{KH}_{2} \mathrm{PO}_{4} 20, \mathrm{MgCl}_{2}$ 3.0, taurine 20, HEPES 10, EGTA 0.5, and glucose $10(\mathrm{pH}=7.4$ adjusted with $\mathrm{KOH})$. The pipette filling solution used for nystatin-perforated patches contained (in $\mathrm{mM}$ ): $\mathrm{KCl} 140, \mathrm{NaCl} 6.0, \mathrm{MgCl}_{2} 1.0$, and HEPES 5.0, $(\mathrm{pH}=7.2$ adjusted with $\mathrm{KOH})$. The pipette filling solution used for the conventional ruptured patch method contained (in $\mathrm{mM}$ ): $\mathrm{K}^{+}$-aspartate 95 , $\mathrm{KCl} 25$, HEPES 5.0, EGTA $10, \mathrm{~K}_{2} \mathrm{ATP} 3.0, \mathrm{CaCl}_{2} 1.0$, and $\mathrm{MgCl}_{2} 1.0(\mathrm{pH}=7.2$ adjusted with $\mathrm{KOH}$ ).

Carvedilol (Daiichi Pharmaceuticals., Tokyo) was dissolved in DMSO and stored as a $10 \mathrm{mM}$ stock solution.

Electrophysiological recordings: The electrical recordings were made using an Axopatch-1D amplifier (Axon Instruments, Foster City, CA, USA). The action potential measurements of the nodal cells were performed using the nystatin permeabilized patch method. Nystatin dissolved in DMSO $(0.1 \mathrm{mg} / \mu \mathrm{l})$ was added to the pipette solution, giving a final concentration of $400 \mu \mathrm{g} / \mathrm{mL}$. The pipette resistance, when filled with this solution, was 1.5-3.0 $\mathrm{M} \Omega$. A liquid junction potential of approximately $10 \mathrm{mV}$ was corrected for. All recordings were made at $32-36^{\circ} \mathrm{C}$. The electrical signals were analyzed using a pCLAMP7 (Axon Instruments). When possible, pooled data were expressed as the mean \pm S.E. Statistical significance was determined by unpaired or paired $t$ tests, as appropriate.

\section{RESULTS}

Effects of carvedilol on automaticity and spontaneous action potentials: The effects of carvedilol on the automaticity and spontaneous action potentials of the SA and AV nodal cells were studied using the nystatin-permeabilized patch method. Figures 1 and 2 show representative tracings recorded before and during superfusion with $1 \mu \mathrm{M}$ of carvedilol. Superfusion with $1 \mu \mathrm{M}$ of carvedilol caused decreases in the spontaneous firing frequency, maximal diastolic potential, and prolonga- 


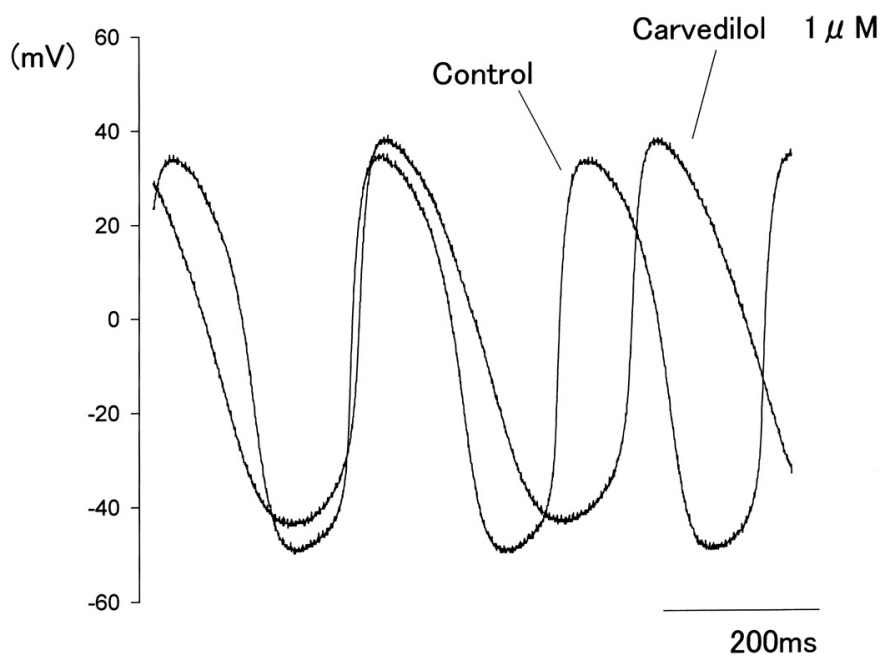

Figure 1. Effect of carvedilol on spontaneous pacing and action potentials in rabbit SA nodal cells. Representative tracing of action potentials from a single SA nodal cell in the presence and absence of $1 \mu \mathrm{M}$ of carvedilol.

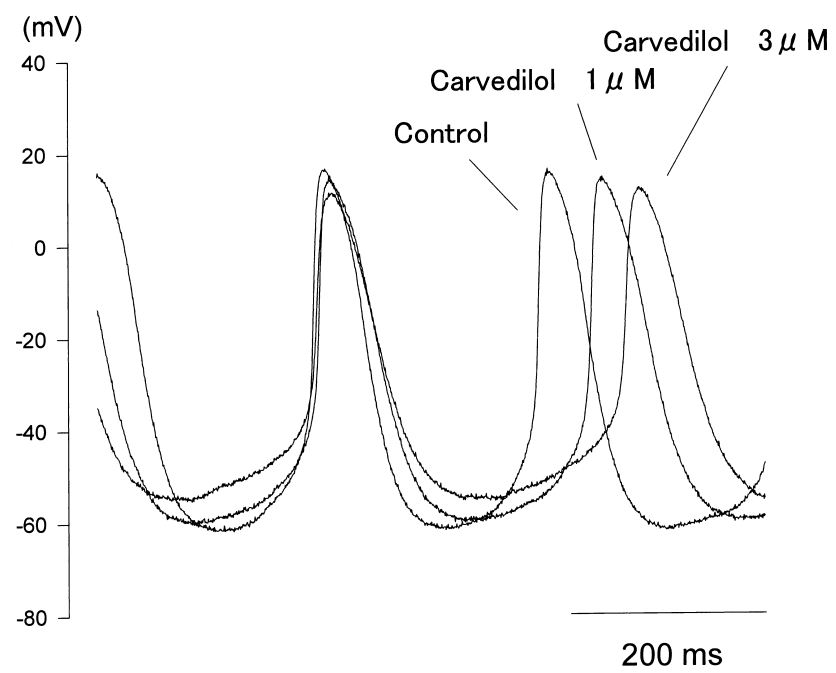

Figure 2. Effect of carvedilol on spontaneous pacing and action potentials in rabbit AV nodal cells. The spontaneous electrical activity of an AV nodal cell before and after superfusion with 1-3 $\mu \mathrm{M}$ of carvedilol.

tion of the action potential duration in both the SA and AV nodal cells. An increase in the concentration of carvedilol to $3 \mu \mathrm{M}$ exaggerated these changes, finally leading to the cessation of any automatic activity in both the SA and AV 
A Control

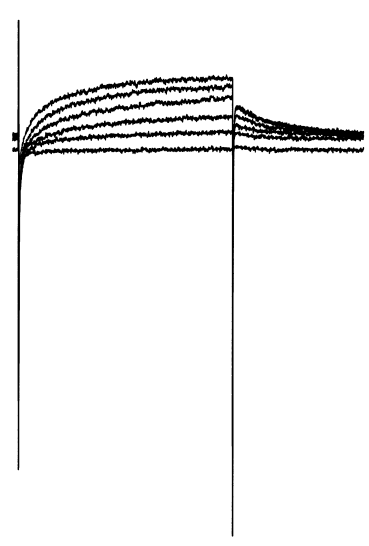

Carvedilol $1 \mu \mathrm{M}$

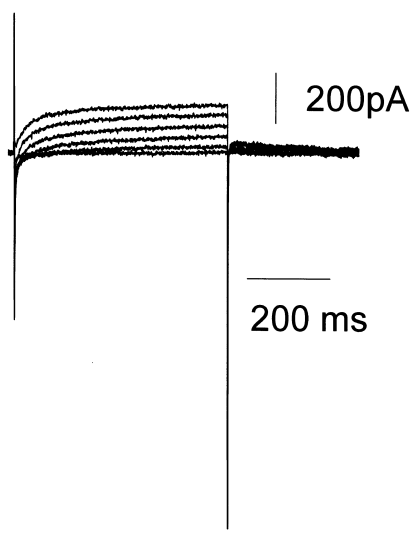

B

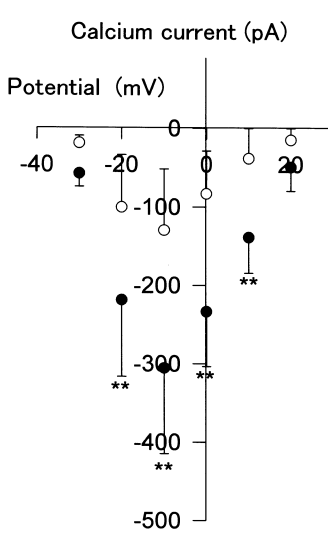

- Control

- Carvedilol $1 \mu \mathrm{M}$
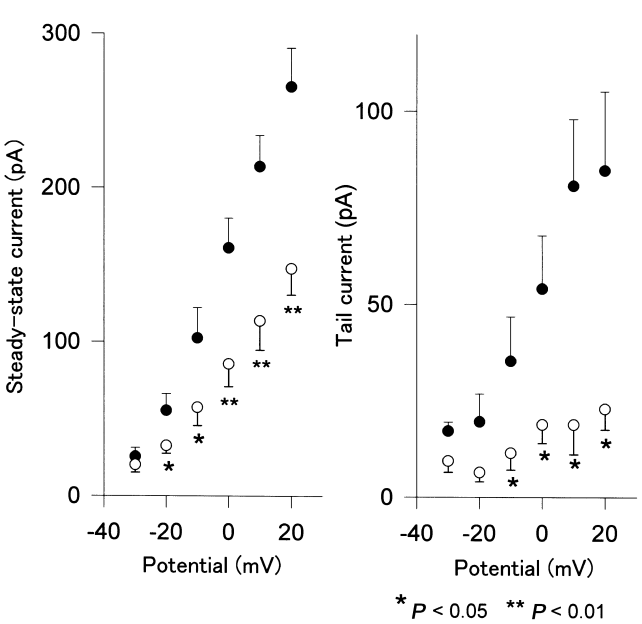

Figure 3. Effects of carvedilol on the L-type $\mathrm{Ca}^{2+}$ current $\left(\mathrm{I}_{\mathrm{Ca}}\right)$ and delayed rectifier $\mathrm{K}^{+}$currents, $\mathrm{I}_{\mathrm{K}}$, in rabbit SA nodal cells. The upper panel shows representative recordings of membrane currents in the presence and absence of carvedilol $(1 \mu \mathrm{M})$. The current-voltage relations for the $\mathrm{I}_{\mathrm{Ca}}$ in the absence and presence of carvedilol are plotted in the lower left panel $(n=4)$. The lower middle and right panels show representative time-dependent outward current and tail currents under control conditions and after the application of carvedilol $(1 \mu \mathrm{M})$.

nodal cells (data not shown). In 7 such experiments in the AV nodal cells, superfusion with $1 \mu \mathrm{M}$ of carvedilol decreased the spontaneous firing frequency, maximal diastolic potential, and maximum rate of depolarization from $214.8 \pm 16.7$ / $\min$ to $170.3 \pm 16.5 / \mathrm{min}(P<0.01),-59.0 \pm 3.0 \mathrm{mV}$ to $-55.9 \pm 3.6 \mathrm{mV}(P<0.05)$, and $4.17 \pm 0.63 \mathrm{~V} / \mathrm{s}$ to $3.54 \pm 0.47 \mathrm{~V} / \mathrm{s}(P<0.05)$, respectively. The action potential duration at $90 \%$ increased from $116.9 \pm 7.0 \mathrm{~ms}$ to $139.8 \pm 10.8 \mathrm{~ms}(P<0.05)$. 
A Control

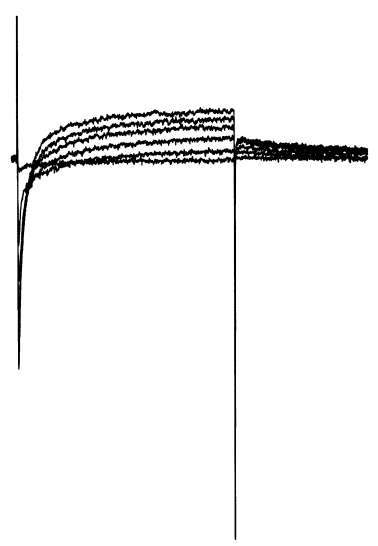

Carvedilol $1 \mu \mathrm{M}$

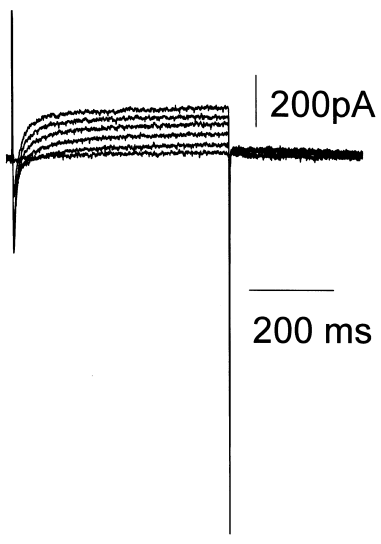

B Calcium current ( $p A)$

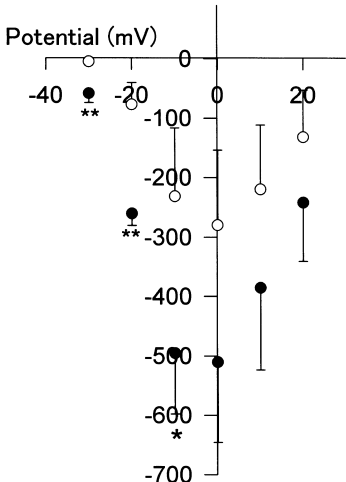

- Control

- Carvedilol $1 \mu \mathrm{M}$
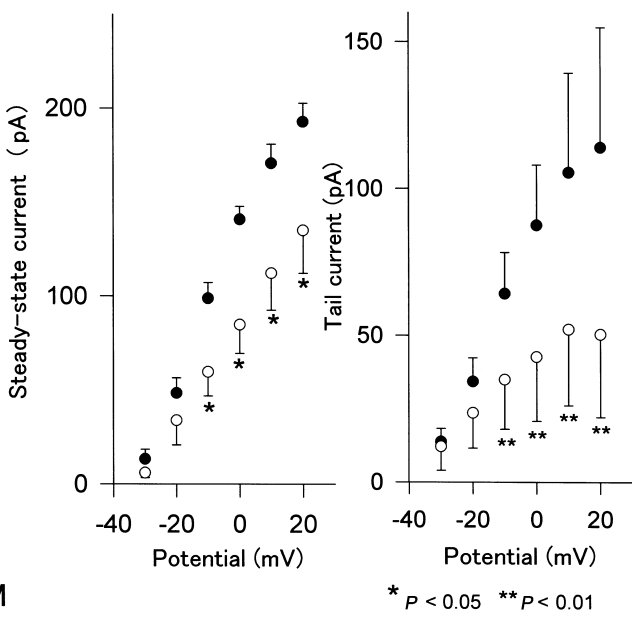

Figure 4. Effects of carvedilol on the L-type $\mathrm{Ca}^{2+}$ current $\left(\mathrm{I}_{\mathrm{Ca}}\right)$ and delayed rectifier $\mathrm{K}^{+}$currents, $\mathrm{I}_{\mathrm{K}}$, in rabbit AV nodal cells. The upper panel shows representative membrane currents under control conditions (left) and after the application of carvedilol $(1 \mu \mathrm{M})$. The voltage clamp protocols were the same as those described in the previous figure. The lower panels show plots of the $\mathrm{I}_{\mathrm{Ca}}$, time dependent outward current, and initial magnitude of the deactivating tail currents under control conditions and after the application of $1 \mu \mathrm{M}$ of carvedilol $(n=4)$.

Similar results were obtained in a total of 2 experiments in the SA nodal cells.

Effects of carvedilol on $\mathrm{L}$-type $\mathrm{Ca}^{2+}$ current $\left(\mathrm{I}_{\mathrm{Ca}}\right)$ and delayed rectifier $\mathrm{K}^{+}$currents, $\mathbf{I}_{\mathbf{K}}$, in rabbit SA and AV nodal cells: The effects of carvedilol on the L-type $\mathrm{Ca}^{2+}$ current $\left(\mathrm{I}_{\mathrm{Ca}}\right)$ and delayed rectifier $\mathrm{K}^{+}$currents, $\mathrm{I}_{\mathrm{K}}$, in the SA and AV nodes were investigated using a conventional membrane-rupturing method. Figures $3 \mathrm{~A}$ and 
4A show the changes in the membrane currents obtained from a step depolarization from a holding potential of $-40 \mathrm{mV}$ to various potential levels before and during the application of $1 \mu \mathrm{M}$ of carvedilol in the SA (3A) and AV (4A) nodal cells. Figures $3 \mathrm{~B}$ and $4 \mathrm{~B}$ show the current-voltage relationships for the $\mathrm{Ca}^{2+}$ current $\left(\mathrm{I}_{\mathrm{Ca}}\right)$, steady-state currents $\left(\mathrm{I}_{\mathrm{SS}}\right)$, and $\mathrm{I}_{\mathrm{K}}$ tail. The results of these 4 experiments on the SA nodal cells are summarized as follows. During the control, the peak $\mathrm{I}_{\mathrm{Ca}}$ recorded at $-10 \mathrm{mV}$ measured $306 \pm 109 \mathrm{pA}$. The addition of $1 \mu \mathrm{M}$ of carvedilol decreased $\mathrm{I}_{\mathrm{Ca}}$ to $130 \pm 78 \mathrm{pA}(P<0.01)$. The $\mathrm{I}_{\mathrm{SS}}$ and $\mathrm{I}_{\mathrm{K}}$ tail recorded during repolarization from -40 to $20 \mathrm{mV}$ decreased from $265 \pm 25 \mathrm{pA}$ to $147 \pm 17 \mathrm{pA}$ and 85 $\pm 20 \mathrm{pA}$ to $23 \pm 5 \mathrm{pA}$, respectively $(P<0.01$ and $P<0.05)$. In the AV nodal cells,

A Control
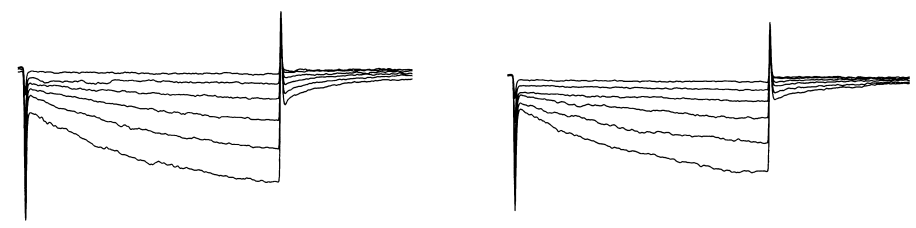

$500 \mathrm{pA}$

$200 \mathrm{~ms}$

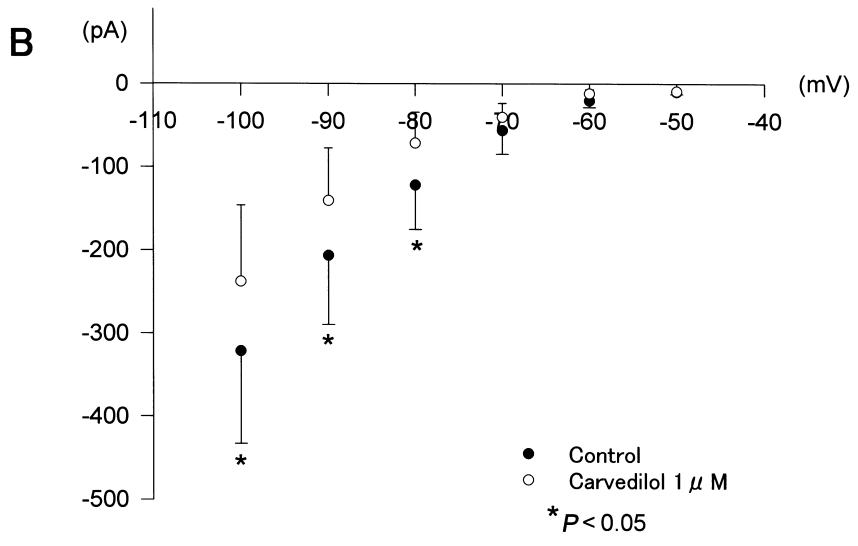

Figure 5. Effect of carvedilol on the hyperpolarization-activated inward current $\left(I_{f}\right)$ in rabbit SA nodal cells. Representative recordings of whole cell currents from a rabbit SA nodal cell. The upper panel shows the currents elicited by hyperpolarizing pulses from -50 to $-100 \mathrm{mV}$ in $10 \mathrm{mV}$ decrements. The current-voltage relationships for the $\mathrm{I}_{\mathrm{f}}$ in the SA node are plotted in the lower panel $(n=8)$. 


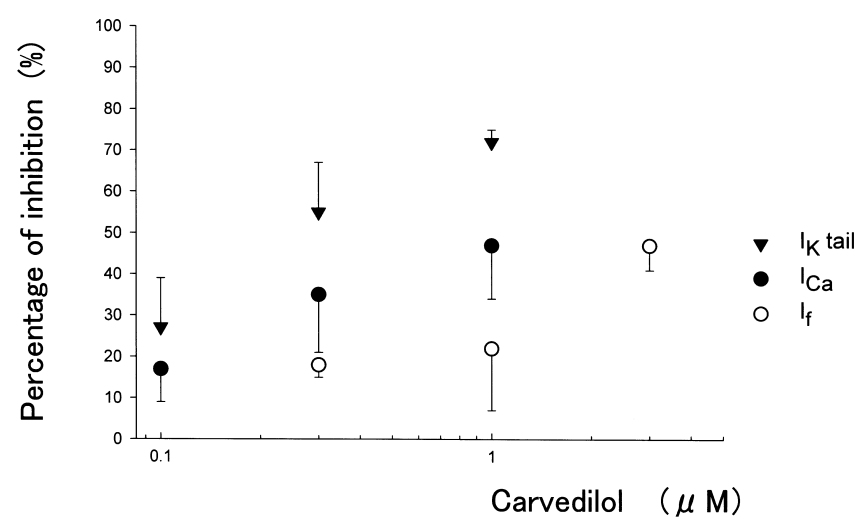

\footnotetext{
Figure 6. Selectivity of the ionic channel block by carvedilol in rabbit SA nodal cells. The axis of the abscissa denotes the concentration of carvedilol. The vertical line denotes the percentage of the inhibition of each current in the presence of carvedilol calculated by the following equation: (1- (current elicited after the administration of carvedilol) / (current elicited in the control state) $) \times 100(\%)$.
}

$\mathrm{I}_{\mathrm{Ca}}$ recorded at $-10 \mathrm{mV}$, and the $\mathrm{I}_{\mathrm{SS}}$ and $\mathrm{I}_{\mathrm{K}}$ tails recorded during repolarization from -40 to $20 \mathrm{mV}$ decreased from $495 \pm 103 \mathrm{pA}$ to $231 \pm 115 \mathrm{pA}, 193 \pm 10 \mathrm{pA}$ to $135 \pm 23 \mathrm{pA}$, and $114 \pm 41 \mathrm{pA}$ to $50 \pm 28 \mathrm{pA}$, respectively $(n=4 ; P<0.05, P$ $<0.05$ and $P<0.01)$.

Effects of carvedilol on the hyperpolarization-activated inward current $\left(I_{f}\right)$ in rabbit SA nodal cells: Figure 5A shows the effect of carvedilol on the hyperpolarization-activated inward current $\left(\mathrm{I}_{\mathrm{f}}\right)$ in the step hyperpolarization from a holding potential of $-40 \mathrm{mV}$ in the SA nodal cells. Figure 5B shows the current-voltage relationships for $\mathrm{I}_{\mathrm{f}}$ during superfusion with $1 \mu \mathrm{M}$ of carvedilol. As shown in Figure $5 \mathrm{~B}, \mathrm{I}_{\mathrm{f}}$ was slightly reduced by carvedilol. When the data in the 8 experiments were averaged, $\mathrm{I}_{\mathrm{f}}$ recorded at $-100 \mathrm{mV}$ decreased from $321 \pm 111 \mathrm{pA}$ to $238 \pm 92$ pA $(P<0.05)$.

Selectivity of the ionic channel block by carvedilol in the rabbit SA node: The percentage of inhibition caused by carvedilol for each current was plotted as a function of the drug concentrations in Figure $6 . \mathrm{I}_{\mathrm{K}}, \mathrm{I}_{\mathrm{Ca}}$, and $\mathrm{I}_{\mathrm{f}}$ were measured on repolarization to $20 \mathrm{mV}$, depolarization to $-10 \mathrm{mV}$, and hyperpolarization to -100 $\mathrm{mV}$ from a holding potential of $-40 \mathrm{mV}$, respectively. Carvedilol blocked such ionic currents in a dose-dependent manner in the decreasing order of $\mathrm{I}_{\mathrm{K}}, \mathrm{I}_{\mathrm{Ca}}$, and $\mathrm{I}_{\mathrm{f}}$ in the SA nodal cells. The percentage inhibition was $72 \%, 47 \%$, and $22 \%$, respectively, at $1 \mu \mathrm{M}$ of carvedilol. In the AV nodal cells, the corresponding reductions were $64 \%\left(\mathrm{I}_{\mathrm{K}}\right)$ and $46 \%\left(\mathrm{I}_{\mathrm{Ca}}\right)$, respectively (data not shown). 


\section{DISCUSSION}

In the present study, we demonstrate that carvedilol suppressed automaticity and repolarization in rabbit nodal cells. This agent prolonged the spontaneous cycle length and reduced the maximum rate of depolarization. In addition, it caused a prolongation of the action potential duration, and decreased the maximal diastolic potential and action potential amplitudes. In the voltage clamp experiments, carvedilol was shown to block $\mathrm{I}_{\mathrm{K}}, \mathrm{I}_{\mathrm{Ca}}$, and $\mathrm{I}_{\mathrm{f}}$, especially $\mathrm{I}_{\mathrm{K}}$. Therefore, this agent was proven to have negative chronotropic effects and class III antiarrhythmic actions.

It was previously reported that carvedilol blocks $\mathrm{I}_{\mathrm{Kr}}$ and $\mathrm{L}$ type Ca currents in rabbit ventricular myocytes. ${ }^{4)}$ Furthermore, carvedilol has been shown to inhibit human ether-a-go-go-related gene (HERG) $\mathrm{K}^{+}$channels. ${ }^{18)}$ However, the mechanisms underlying the possible negative chronotropic actions of this agent have not yet been fully elucidated. This is the first study demonstrating that carvedilol possesses direct negative chronotropic effects. Although we did not conduct experiments using blockers of the slowly activating component of the delayed rectifier, $\mathrm{I}_{\mathrm{Ks}}$, the majority of the blocked components by carvedilol were considered to be $\mathrm{I}_{\mathrm{Kr}}$ since it had been reported that the contribution of $\mathrm{I}_{\mathrm{Ks}}$ to the spontaneous pacemaker rate was small under control conditions in the rabbit SA node, and $\mathrm{I}_{\mathrm{Kr}}$ which predominates in the rabbit AV node was blocked to a submaximal degree by carvedilol. ${ }^{19-21)}$ Cheng, et al reported that carvedilol exhibited a bell-shaped frequency and dose-response curve of the action potential duration. ${ }^{4)}$ In our experiments, carvedilol prolonged the action potential duration in a dose-dependent fashion in the range of 0.1-3 $\mu \mathrm{M}$, which was considered to be caused by a greater $\mathrm{I}_{\mathrm{K}}$ block in comparison to the $\mathrm{I}_{\mathrm{Ca}}$ block in that dose range.

The effects of adrenergic stimulation of the SA node have been reported to make the slope of the slow diastolic depolarization steeper, increase the maximum rate of depolarization, and shorten the action potential duration. Hence, one of the mechanisms of the antiarrhythmic action of $\beta$-adrenergic blocking agents is considered to be to antagonize those effects in the presence of $\beta$-adrenergic stimulation. Indeed, it has been shown that atenolol has no effect on the repolarization of the SA node, whereas it has an inhibitory effect on the acceleration of the repolarization phase in the presence of $\beta$-receptor stimulation. ${ }^{22)}$ On the other hand, some $\beta$-adrenergic blocking agents have been demonstrated to have a direct membrane action which differs from the membrane stabilizing action of a $\mathrm{Na}$ channel block. Namely, it has been demonstrated that pindolol and propranolol cause a prolongation of the action potential duration and negative chronotropic effect in the rabbit SA node, although the concentration used in that study was 550 times higher than that in clinical use. ${ }^{23)}$ The study also demonstrated that both 
drugs inhibited the slow inward current and time-dependent outward current, but produced different actions on $\mathrm{I}_{\mathrm{f}}$ (propranolol inhibited $\mathrm{I}_{\mathrm{f}}$, but pindolol did not affect it). Furthermore, the $\alpha_{1}$ - and $\beta$-adrenoreceptor blocking drugs labetalol and medroxalol have been shown to reduce the maximum rate of depolarization and prolong the action potential duration in the rabbit SA node. ${ }^{24)}$ Thus, it has been suggested that some $\beta$-adrenoreceptor blocking drugs have a potency equal to class III or class IV antiarrhythmic actions.

In the present study, the effect of carvedilol on the action potential was evident at $0.1 \mu \mathrm{M}$. The therapeutic range of the plasma concentration of carvedilol has been reported to be $0.1-0.6 \mu \mathrm{M}^{25,26)}$ Therefore, carvedilol is considered to have a direct membrane action like that of class III antiarrhythmic drugs, with a negative chronotropic effect. On the other hand, the contribution of the $\mathrm{I}_{\mathrm{f}}$ block in the negative chronotropic effect caused by carvedilol may be small based on our experimental results.

It is well-known that nodal tissue is related to some types of reentrant tachyarrhythmias such as AV nodal reentrant tachycardia, AV reentrant tachycardia using an accessory pathway, and sinus nodal reentrant tachycardia. Furthermore, it has recently been suggested that tissue similar to nodal cells is present in the pulmonary veins in experimental animals and in human pulmonary vein preparations in patients with atrial fibrillation. ${ }^{27-29)}$ Karle, et al reported that the potency of carvedilol for an $\mathrm{I}_{\mathrm{Kr}}$ block encoded by the HERG might be beneficial for ventricular arrhythmias, thereby resulting in the positive outcomes of various clinical trials in patients with chronic heart failure and postmyocardial infarction. ${ }^{18)}$ Since supraventricular tachyarrhythmias leading to atrial fibrillation can affect cardiac function, carvedilol's effect on $\mathrm{I}_{\mathrm{K}}$ and $\mathrm{I}_{\mathrm{Ca}}$ observed in our study, at least in part, may be responsible for the good prognosis in various clinical trials. Of course, carvedilol has a number of ancillary activities, including antioxidant, anti-inflammatory, and antiapoptotic properties in addition to the well-known properties, ${ }^{2-3,5)}$ and hence, some unknown antiarrhythmic activities might exist. Further studies will be required to elucidate these points.

In conclusion, effective doses of carvedilol have classical class III antiarrhythmic actions and a negative chronotropic effect resulting from the inhibition of $\mathrm{I}_{\mathrm{K}}$ and $\mathrm{I}_{\mathrm{Ca}}$ in rabbit $\mathrm{SA}$ and $\mathrm{AV}$ node cells. Both actions may be effective in the treatment of supraventricular tachyarrhythmias in the clinical setting.

Limitations: It has been demonstrated that the electrical characteristics, including the ion channel activity of the SA and AV nodes, are heterogeneous. ${ }^{30-32)}$ In the present study, we attempted to isolate and use spindle and ovoid cells of the SA and AV nodes, respectively. However, some rod cells, which are slightly different electrically from true nodal cells, might have been included in some experiments, and this might have caused the variability in the effects of carvedilol on 
the ionic currents in the SA and AV nodal cells. This may be an important limitation in the quantitative analysis of the drug in this study. Further studies using other agents such as $\mathrm{I}_{\mathrm{Kr}}$ blockers or $\mathrm{I}_{\mathrm{Ks}}$ blockers will be needed to clarify this point.

\section{REFERENCES}

1. Ruffolo RR Jr, Gellai M, Hieble JP, Willette RN, Nichols AJ. The pharmacology of carvedilol. Eur J Clin Pharmacol 1990; 38: S82-8. (Review)

2. Yaoita H, Sakabe A, Maehara K, Maruyama Y. Different effects of carvedilol, metoprolol, and propranolol on left ventricular remodeling after coronary stenosis or after permanent coronary occlusion in rats. Circulation 2002; 105: 975-80.

3. Lysko PG, Webb CL, Gu JL, Ohlstein EH, Ruffolo RR Jr, Yue TL. A comparison of carvedilol and metoprolol antioxidant activities in vitro. J Cardiovasc Pharmacol 2000; 36: 277-81.

4. Cheng J, Niwa R, Kamiya K, Toyama J, Kodama I. Carvedilol blocks the repolarizing $\mathrm{K}^{+}$currents and the Ltype $\mathrm{Ca}^{2+}$ current in rabbit ventricular myocytes. Eur J Pharmacol 1999; 376: 189-201.

5. Okafor CC, Perreault-Micale C, Hajjar RJ, et al. Chronic treatment with carvedilol improves ventricular function and reduces myocyte apoptosis in an animal model of heart failure. BMC Physiol 2003; 3: 6.

6. Doughty RN, Whalley GA, Gamble G, MacMahon S, Sharpe N. Left ventricular remodeling with carvedilol in patients with congestive heart failure due to ischemic heart disease. Australia-New Zealand Heart Failure Research Collaborative Group. J Am Coll Cardiol 1997; 29: 1060-6.

7. Palazzuoli A, Bruni F, Puccetti L, et al. Effects of carvedilol on left ventricular remodeling and systolic function in elderly patients with heart failure. Eur J Heart Fail 2002; 4: 765-70.

8. Packer M, Bristow MR, Cohn JN, et al. The effect of carvedilol on morbidity and mortality in patients with chronic heart failure. US Carvedilol Heart Failure Study Group. N Engl J Med 1996; 334: 1349-55.

9. Packer M, Colucci WS, Sackner-Bernstein JD, et al. Double-blind, placebo-controlled study of the effects of carvedilol in patients with moderate to severe heart failure. The PRECISE Trial. Prospective Randomized Evaluation of Carvedilol on Symptoms and Exercise. Circulation 1996; 94: 2793-9.

10. Colucci WS, Packer M, Bristow MR, et al. Carvedilol inhibits clinical progression in patients with mild symptoms of heart failure. US Carvedilol Heart Failure Study Group. Circulation 1996; 94: 2800-6.

11. Bristow MR, Gilbert EM, Abraham WT, et al. Carvedilol produces dose-related improvements in left ventricular function and survival in subjects with chronic heart failure. MOCHA investigators. Circulation 1996; 94: 2807-16.

12. Packer M, Fowler MB, Roecker EB, et al. Effect of carvedilol on the morbidity of patients with severe chronic heart failure: results of the carvedilol prospective randomized cumulative survival (COPERNICUS) study. Circulation 2002; 106: 2194-9.

13. Basu S, Senior R, Raval U, van der Does R, Bruckner T, Lahiri A. Beneficial effects of intravenous and oral carvedilol treatment in acute myocardial infarction. A placebo-controlled, randomized trial. Circulation 1997; 96: 183-91.

14. Senior R, Muller-Beckmann B, DasGupta P, van der Does R, Lahiri A. Effects of carvedilol on ventricular arrhythmias. J Cardiovasc Pharmacol 1992; 19: S117-21.

15. Brunvand H, Frlyland L, Hexeberg E, Rynning SE, Berge RK, Grong K. Carvedilol improves function and reduces infarct size in the feline myocardium by protecting against lethal reperfusion injury. Eur J Pharmacol 1996; 314: 99-107.

16. Hoher M, Friedrich M, Sommer T, et al. Effects of carvedilol on left ventricular function and arrhythmias during repeated short-time myocardial ischemia in experimental pigs. Z Kardiol 1989; 78 (suppl): 7-15.

17. Bril A, Tomasi V, Laville MP. Antiarrhythmic effects of carvedilol in rat isolated heart subjected to ischemia and reperfusion. Pharmacol Commun 1995; 5: 281-300.

18. Karle CA, Kreye VA, Thomas D, et al. Antiarrhythmic drug carvedilol inhibits HERG potassium channels. Cardiovasc Res 2001; 49: 361-70. 
19. Lei M, Cooper PJ, Camelliti P, Kohl P. Role of the 293b-sensitive, slowly activating delayed rectifier potassium current, $\mathrm{i}_{\mathrm{Ks}}$, in pacemaker activity of rabbit isolated sino-atrial node cells. Cardiovasc Res 2002; 53: 68-79.

20. Howarth FC, Levi AJ, Hancox JC. Characteristics of the delayed rectifier K current compared in myocytes isolated from the atrioventricular node and ventricle of the rabbit heart. Pflugers Arch 1996; 431: 713-22.

21. Sato N, Tanaka H, Habuchi Y, Giles WR. Electrophysiological effects of ibutilide on the delayed rectifier $\mathrm{K}^{+}$ current in rabbit sinoatrial and atrioventricular node cells. Eur J Pharmacol 2000; 404: 281-8.

22. Tohse N. Analysis of membrane current system involved in the inotropic effects mediated by $\alpha$-adrenoceptors in the heart. Hokkaido Igaku Zasshi 1988; 63: 754-71. (Japanese)

23. Satoh H. Different actions between pindolol and propranolol on the ionic currents in spontaneously beating rabbit sino-atrial node cells. J Cardiovasc Pharmacol 1995; 25: 967-72.

24. Dukes ID, Vaughan Williams EM. Electrophysiological effects of $\alpha$-adrenoceptor antagonists in rabbit sinoatrial node, cardiac Purkinje cells and papillary muscles. Br J Pharmacol 1984; 83: 419-26.

25. McPhillips JJ, Schwemer GT, Scott DI, Zinny M, Patterson D. Effects of carvedilol on blood pressure in patients with mild to moderate hypertension. A dose response study. Drugs 1988; 36 (suppl): 82-91.

26. Morgan T, Anderson A, Cripps J, Adam W. Pharmacokinetics of carvedilol in older and younger patients. J Hum Hypertens 1990; 4: 709-15.

27. Cheung DW. Electrical activity of the pulmonary vein and its interaction with the right atrium in the guinea-pig. J Physiol 1981; 314: 445-56.

28. Ehrlich JR, Cha TJ, Zhang L, et al. Cellular electrophysiology of canine pulmonary vein cardiomyocytes: action potential and ionic current properties. J Physiol 2003; 551: 801-13.

29. Perez-Lugones A, McMahon JT, Ratliff NB, et al. Evidence of specialized conduction cells in human pulmonary veins of patients with atrial fibrillation. J Cardiovasc Electrophysiol 2003; 14: 803-9.

30. Munk AA, Adjemian RA, Zhao J, Ogbaghebriel A, Shrier A. Electrophysiological properties of morphologically distinct cells isolated from the rabbit atrioventricular node. J Physiol 1996; 493: 801-18.

31. Lei M, Honjo H, Kodama I, Boyett MR. Heterogeneous expression of the delayed-rectifier $\mathrm{K}^{+}$currents $\mathrm{i}_{\mathrm{K}, \mathrm{r}}$ and $\mathrm{i}_{\mathrm{K}, \mathrm{S}}$ in rabbit sinoatrial node cells. J Physiol 2001; 535: 703-14.

32. Boyett MR, Honjo H, Kodama I. The sinoatrial node, a heterogeneous pacemaker structure. Cardiovasc Res 2000; 47: 658-87. (Review) 